\title{
Increasing EFL Learner Participation through Eliciting Language: Insights from Conversation Analysis
}

\author{
Marco Cancino \\ Universidad Andres Bello \\ Correspondence concerning this article should be addressed to Marco Cancino, Department of English \\ Language, Universidad Andres Bello, Fernandez Concha 700, Las Condes, Santiago, Chile. \\ E-mail:marco.cancino@unab.cl
}

\begin{abstract}
The idea that interaction shapes learning in the second language classroom by increasing opportunities for participation, and that teachers can achieve this by adequately eliciting language from learners has been discussed in the literature. However, research specifying interactional resources deployed by teachers when eliciting language from their learners has been scarce. To this end, the present study used conversation analysis to examine the interactional resources produced in the elicitation of questions belonging to a specific lesson stage, namely, the 'classroom context mode' (CCM). In the CCM, fluency and meaningful exchanges are encouraged, and learners are prompted to talk about their feelings, emotions, and experiences, which represent a fruitful interactional juncture for eliciting learner language. The data collected in the present study come from four teachers and their students in an adult English as a foreign language (EFL) classroom at a language institute in Chile. The participants were audio-recorded over a total of six lessons that were delivered as part of a 10-week course. From the analysis, two novel elicitation resources, namely the 'effective management of closed questions' and the 'use of open referential questions as initiators of CCM', were found to promote a facilitator-oriented approach to teaching. The pedagogical value of these resources is discussed in terms of their potential for initiating and sustaining a CCM, and their inclusion in a framework that seeks to develop teachers' classroom interactional competence.
\end{abstract}

Keywords: eliciting language, classroom context mode, classroom interactional competence, conversation analysis, teacher talk

\section{Introduction}

Studies focusing on the provision of learning opportunities have reported specific ways in which interaction can shape learning in the second language classroom (Markee, 2015; Seedhouse \& Walsh, 2010; Sert, 2015; Walsh, 2002, 2012, 2013; Waring, 2008; 2009, 2011, 2019; Waring, Reddington, \& Tadic, 2016). More specifically, it has been found that teachers use an array of interactional strategies in order to elicit answers from their learners, which is an important part of the linguistic exchanges in the classroom (Lee, 2006; Waring, 2012). The most typical way in which this is done in the language classroom is by asking questions, as teachers prompt learners to respond in order to assess their learning, check comprehension, introduce a new topic, and improve second language ability (Jafari, 2013). A teacher's ability to utilise a range of question types and understand the functions being served by them is an important feature of teachers' classroom interactional competence (CIC) (Walsh, 2006), which highlights the role of the teacher in successfully eliciting language from learners and encouraging patterns of communication that can promote co-constructed interactions. Question and answer sequences where teachers ask most of the questions are a very common feature of second language classrooms and represent another way for teachers to control the discourse (Walsh, 2011). Regarding the types of questions that are asked by teachers, Tsui (1995) identifies two main sets of categories; 'open' and 'closed' questions, and 'display' and 'referential' questions. The first distinction addresses the type of response elicited from learners. Open questions have a range of acceptable answers (e.g. 'how was your weekend?') whilst closed questions have only one acceptable answer or a very limited range of answers (e.g. 'did you have a good weekend?'). Tsui (1995) posits that closed questions are more restrictive than open questions because they do not force the student to 
produce a great amount of output. The second set of categories discussed by Tsui has been widely researched and focuses on the nature of interaction that is potentially generated by the questions. A display question is a question for which the teacher knows the answer and is asked to evaluate learners' knowledge (e.g. 'what colour is my jacket?') whilst a referential question is a genuine question for which the teacher does not know the answer (e.g. 'when are you having the party?'). In language classroom settings, it has been found that referential questions are typically more tailored to elicit 'natural' responses from learners than display questions because they elicit extended learner turns and create space for further learner talk (Brock, 1986; Lee, 2006; Tsui, 1995; Walsh, 2006, 2013). It must be noted that the production of referential questions requires not only more cognitive effort from the learner (Nunan, 1989) but also from the teacher (Thornbury, 1996), which may explain to some extent the historic pervasiveness of display questions in language classrooms. However, if discourse in the classroom is not regarded as a static and unchanging context but as a dynamic and shifting set of micro-contexts, the pedagogical distinction between referential and display questions may have less value when the relationship between pedagogical goals and the different functions served by these questions are not factored in. As Walsh (2011) states, display questions are adequate when teachers seek to check understanding or confirm what learners already know; when the goal is to promote discussion or oral fluency, referential questions are more appropriate. Thus, the effectiveness of display or referential questions can be better addressed when they are aligned with specific pedagogical goals that will warrant their use at a particular time (Cullen, 1998; Walsh, 2006, 2013).

This study took place in a Chilean adult EFL setting. In Chile, EFL is taught compulsorily (114 hours per year) starting from 5 th grade in primary education until 12 th grade in secondary education. The national curriculum and government agendas have made efforts to transform the country into a bilingual nation that can play a prominent role in globalised markets (Glas, 2008). The Ministry of Education encourages the use of the foreign language in the classroom, and the four language skills are given equal weight in the curriculum (Ministerio de Educación, 2009). Furthermore, initiatives such as English Open Doors have been proposed to provide continuing education for teachers and create a generation of independent learners of English who are functionally bilingual (Matear, 2008). However, language teachers are required to provide a great deal of information to learners by means of textbook activities such as grammar and vocabulary tasks and listening comprehension exercises. This prevents learners from asking and replying to authentic questions and also prevents teachers from creating opportunities to elicit authentic language. These issues, together with the insufficient number of hours allocated to learning English in municipal schools (Barahona, 2016) may explain to some extent the poor performance of Chilean learners on international proficiency tests when compared to other countries in the region (Gómez \& Pérez, 2015).

\section{Studies on language elicitation in EFL/ESL settings}

It has been found that teachers can increase opportunities for learning by adequately eliciting language from learners. For example, Markee (2004) used a conversation analytic approach to describe the structure of the 'zones of interactional transition' - that is, talk that occurs when teachers make the transition from one speech exchange system to another (i.e. from learner-learner talk to form-focused work led by the teacher). Markee focuses on counter questions, which are typically defined as questions that are used to immediately respond to a learner question in order to keep control of the classroom agenda. In his analysis, Markee demonstrates that the talk taking place in the boundaries of each system can potentially cause interactional trouble in the ensuing talk and negatively affect learning. In line with this, Lee and $\mathrm{Ng}$ (2010) sought to find out whether teachers' interactional strategies were one of the factors influencing learners' reticence to communicate. They analysed two ESL lessons taught by two local Hong Kong secondary teachers characterised by two distinct interactional patterns. They found that offering learners opportunities to contribute to the interaction and managing communication through a 'facilitator-oriented' approach - that is, a type of teacher intervention that utilises devices such as the use of referential questions, scaffolding, and use of back-channel feedback in order to facilitate interaction - encouraged participation in these learners. This facilitator-oriented approach is crucial to increasing learner participation, and needs to be further researched to identify specific interactional resources embedded in referential questions produced by teachers to elicit language. With a specific focus on the pedagogical potential of display questions as central resources in the language classroom, Lee (2006) performed a sequential analysis of 36 hours of ESL class sessions from different courses. He found that display questions can provide the necessary resources to navigate the discourse by means of multiple initiation-responseevaluation sequences, and that display questions become interactionally relevant by means of the topics being 
introduced and the meanings being clarified. Lee concluded that display questions should not be dismissed as ineffective teaching tools, without assessing the situated context in which they take place, and the interactional devices that are utilised by teacher and learners to reach understandings. In other words, the (pedagogical) context in which any interaction takes place must be addressed before generating a priori assessments regarding the effectiveness of the language choices made by teachers to elicit learner talk. Similarly, Waring (2012) assessed how yes-no questions (e.g. 'Do you have any questions?') may work as 'understanding-checks' in the language classroom. She used a conversation analytic approach to analyse 28 hours of interaction in an English as a second language classroom. The findings suggested that the same yes-no questions may be deployed to check understanding and also to close down a sequence. In addition, learners' decisions whether or not to continue talking in those cases may be related to their lack of competence to do so. As Waring argues, although these types of yes-no questions have been treated as a type of referential question, they were found to accomplish different interactional tasks in several sequential environments. Teachers may also orient to diverse pedagogical goals as they produce understanding-checks. Indeed, simply deciding what questions to ask in the language classroom may not be enough, as the interactional circumstances in which a single question is asked and managed by interactants (e.g. teacher/learner silence) may produce a range of responses that are locally contingent (Waring, 2012).

Therefore, taking into account a perspective that highlights learning as participation, and the relevance of utilising appropriate elicitation techniques to promote opportunities for learning in specific learning contexts, the present study sought to examine and detail aspects of interaction focusing on elicitation techniques in the adult English as a foreign language (EFL) classroom. The main research questions that were addressed in the present study are:

1. What is the nature of specific elicitation resources utilised by EFL teachers?

2. How do EFL teachers' interactional decisions regarding elicitation hinder/facilitate opportunities for participation and learning?

\section{Materials and Methods}

\section{Context of the Study and Participants}

The data collected in the present study come from four Chilean teachers and their students in an adult EFL classroom at a language institute in Chile. The participant teachers had at least one year of experience teaching in that institution, and their total amount of experience teaching EFL ranged from two to four years. The students were Chilean adult professionals who sought to improve their language proficiency in order to access international scholarships and better job prospects. The number of students in each group ranged between ten and twelve. The participants were audio-recorded in a total of eight lessons (two 30-minute lessons per teacher) that were delivered as part of a 10-week course. From the total amount of data, six representative extracts were selected taking into account Walsh's (2006) classification for classroom contexts, namely, Managerial, Materials, Skills and systems, and Classroom context. These modes are locally negotiated micro-contexts that shape the moment-by-moment interactions in a lesson. They have a clear pedagogical goal, distinctive interactional features, and are representative of the teacher-fronted interaction that takes place in the second language classroom (Walsh, 2006). The six extracts in the present study were identified as containing interactions belonging to the 'classroom context mode' (CCM). This mode was found suitable for analysis because the pedagogical goals that are particular to this mode involve developing fluency and meaningful exchanges, so learners were encouraged to talk about their feelings, emotions, experiences, and attitudes that are embedded in their own cultural backgrounds. The CCM should be encouraged and researched in EFL contexts because "it is a facet of classroom interaction whose intricacies are usually left aside in teacher training courses" (Cancino, 2017, p. 61). Thus, the specific learning object in the extracts is not the learning of the formal features of the language, but rather, developing fluency and communication.

\section{Data Analysis}

In order to carry out the analysis, the present study utilised Conversation Analysis (CA) to illustrate the way in which teachers elicit questions and the impact this has on opportunities for learning and participation. CA is a 
data-driven approach that seeks to provide empirical accounts of oral interaction that can illustrate systematic features present in the sequencing organisation of talk, and explain how people use such features as part of social activities (Hutchby \& Wooffitt, 2008; Lazaraton, 2004). Hence, this approach regards functions of language as a means for social interaction (Sacks, Schegloff, \& Jefferson, 1974) that shape turn-taking features embedded in social contexts. The turn-taking resources are used by individuals to enact context-bound meanings that need to be understood in order to navigate locally managed interactions. In this respect, CA researchers have access to the same competences used by interactants as they try to make sense of an interaction, i.e. reach 'intersubjectivity' (Seedhouse, 2004). The methods that learners have at their disposal are crucial to articulate meanings and maintain social order (Pekarek Doehler, 2010), and a conversation analytic approach is equipped to surface those methods.

Conversation analytic approaches to second language acquisition have underscored the importance of interactions as a source of learning, and as a social phenomenon that allows learners to deploy a wide array of interactional devices to reach mutual understanding (Kasper \& Wagner, 2011; Ortega, 2011). An interactional device that is relevant to the present study is the Turn Constructional Unit (TCU), which are turns at talk that are highly dependent on sequential contexts, and can consist of several types of linguistic units, such as sentences, clauses, or lexical constructions, and non-verbal elements such as silence, laughter, or body movements (Sacks et al., 1974). Thus, learner TCUs were identified and discussed taking into account the type of elements they contain (verbal, non-verbal), and the way in which the teacher managed them in a particular sequence.

Transcription conventions were based on Atkinson and Heritage (1984) and modified to meet the needs of the present study (see Appendix). An analysis of the extracts was conducted following Ellis and Barkhuizen's (2005) set of guidelines regarding data analysis within the CA approach. The guidelines contain a series of methodological steps that take into account the institutional nature of classroom talk. In order to accomplish this, the authors combined the guidelines proposed by Pomeranz and Fehr (1997) - which help CA researchers identify and describe the practices that allow participants in ordinary conversation to reach understandings with suggestions made by Heritage (1997) - designed to describe institutional interaction. The incorporation of elements addressing institutional interaction in the analysis, as Ellis and Barkuizen (2005) state, is a more appropriate approach to analysing teacher and learner talk, given their goal-oriented nature. The steps presented by Ellis and Barkuizen (2005) focus on aspects that need to be taken into account for the selection of a sequence, the characterization of the actions, and the understandings displayed by participants in the sequence, along with the roles accomplished by the interactants. Ellis and Barkuizen (2005) underscore that the guidelines are not comprehensive and should not be followed in a systematic order. Analysis, they write, "is a slow, gradual process which requires repeated listening to the recorded conversation, continuous refinement of the transcript and constant searching for deeper understandings" (p. 221). Therefore, in the present study, this set of steps guided the researcher toward the description of a "conversational 'practice' and the knowledge that conversational participants employ in conducting the practice"” (Lazaraton, 2004, p. 57). Their application yielded information about the way in which opportunities for participation and learning come in and out of existence in the language classroom by means of elicitation.

\section{Procedure}

Due to accessibility and availability issues, convenience sampling was used to select the participant teachers. After selecting the teachers from a list of potential participants, the researcher was informed by administrators that those teachers were available and had agreed to have their lessons audio-recorded. For each teacher, the lessons were recorded two weeks apart, with the first lesson being recorded three weeks after the start of the course. Before the recording sessions started, the researcher met with the participant teachers and explained in general terms the type of research being carried out. Then, the researcher introduced himself to the classes and explained the same points in order to collect the consent forms. Following this, the researcher placed a microphone on the teacher's desk and left the room for the duration of the lesson, which was done so as to keep the interaction in these classrooms as genuine as possible by minimising external disruptions. In order to answer the research questions, the data contained lessons and activities in the CCM that aimed mainly to develop oral fluency and teacher-fronted interaction. Thus, each participant teacher was audio-recorded in two 30-minute lessons, which generated approximately 240 minutes of audio recording in total. Then, data portraying teacherstudent interactions in the CCM were fully transcribed and analysed by means of conversation analysis. 


\section{Results and Discussion}

In this section, specific elicitation features that teachers used in the CCM are analysed and discussed. In the CCM, whilst learners are encouraged to produce extended turns, the teacher contributes short turns that will typically take the form of direct repair (fixing a breakdown in communication), content feedback (providing feedback on meaning, as opposed to feedback on form), and backchannel feedback. In particular, two eliciting resources were found to influence learner participation in this mode. These refer to the effective management of closed questions and the use of open referential questions as initiators of CCM.

\section{Effective Management of Closed Questions}

As previously stated, closed questions have only one acceptable answer, and are said to be more restrictive in terms of the amount of output that they demand from learners as opposed to open questions, which allow for a range of acceptable answers (Tsui, 1995). The manner in which these questions are asked and what the teacher does next can influence opportunities for learning and participation. First, a typical example portraying the limited range of responses for a closed question is presented in Extract 1. The lesson is part of an elementary level class where learners are discussing favourite films and where L7 has mentioned one particular film she likes, Spirit ${ }^{1}$.

\section{Extract 1: T1. Story.}

\begin{tabular}{|c|c|c|}
\hline $1 \rightarrow$ & T1: & [do you] like that film? \\
\hline 2 & L7: & {$[>$ music $<]$ muc- music, history } \\
\hline 3 & T1: & the story \\
\hline 4 & L7: & the story?, eh:: (.) music? eh:: photography? \\
\hline 5 & T1: & okay? \\
\hline 6 & L7: & eh:: (.) eh the history $\mathrm{i}-\mathrm{eh}:$ : spectacular. \\
\hline 7 & T1: & okay? \\
\hline 8 & L7: & si: $[()]$ \\
\hline 9 & & yes $[()]$ \\
\hline $\begin{array}{l}10 \rightarrow \\
11 \\
12\end{array}$ & T1: & $\begin{array}{l}\text { [ye:s] the story is very good (.) ((addressing L2)) have } \\
\text { you seen that film? (0.8) Spirit? (.) [about] the ho:rse } \\
\text { and everything? }\end{array}$ \\
\hline 13 & L2: & [yes] \\
\hline 14 & L2: & ah yes \\
\hline $\begin{array}{l}15 \\
16\end{array}$ & T1: & $\begin{array}{l}\text { ye:s, it's a very good movie (.) what about you? } \\
((\text { addressing L4)) }\end{array}$ \\
\hline
\end{tabular}

In line 1, T1 asks an open question to L7 as she wants to know the reasons why L7 likes the film. This prompts L7 to produce an answer that is delivered in four TCUs. L7's utterances lack verbal forms, and contain lexical errors, but the open question prompted L7 to make an effort to provide an answer. Then, in line 10, T1 asks L2 a closed question in the form of a yes/no question that is connected to the previous topic ('have you seen that film?'). This closed question generates two answers. The first one overlaps T1's further provision of details, and the second one is delivered after T1's turn. In both instances, L7 focuses on the specific type of answer that is required by a yes/no question, that is, L7 produces 'yes' in line 13, and 'ah yes' in line 14. L2's answer is met with content feedback by $\mathrm{T} 1$ in line 15, which does not prompt another turn by L2. After providing content feedback, the initiation-response-follow-up (IRF) (Sinclair, \& Coulthard, 1975) sequence between T1 and L2 is finished and $\mathrm{T} 1$ addresses another learner. It can be noticed in the interaction that the closed question asked by T1 prompted L2 to provide 'yes' as an answer and stop contributing further to the discussion. Due to the content feedback provided by T1 (line 15), L2 oriented to her role in the IRF sequence as fulfilled, so it was not necessary

\footnotetext{
${ }^{1}$ It must be noted that in some of the extracts, the CCM is displayed as a side-sequence, i.e., 'the brief departure from one mode to another and back again' (Walsh, 2006, p. 65). In the analysis, when this departure occurs, it will be from the 'Materials mode' to a CCM. The Materials mode is a pedagogical mode where the teacher's and learners' discourse are being dictated by the materials being used, where the initiation-response-feedback pattern is prominent, and where the teacher evaluates learners' contributions by providing form-focused feedback (Walsh, 2006).
} 
to expand her contribution. This sequence suggests that when the goal is to promote communication and fluency, providing content feedback after a closed question has been answered in the shortest form possible may not be the most efficient way to elicit learner talk.

A similar treatment of closed questions can be seen in Extract 2. This interaction belongs to a lesson with intermediate-level learners. This extract portrays a mode side sequence where the teacher momentarily switches from a context in which they are doing textbook activities (Materials mode) ${ }^{2}$ to a CCM.

Extract 2: T4. Dinner.

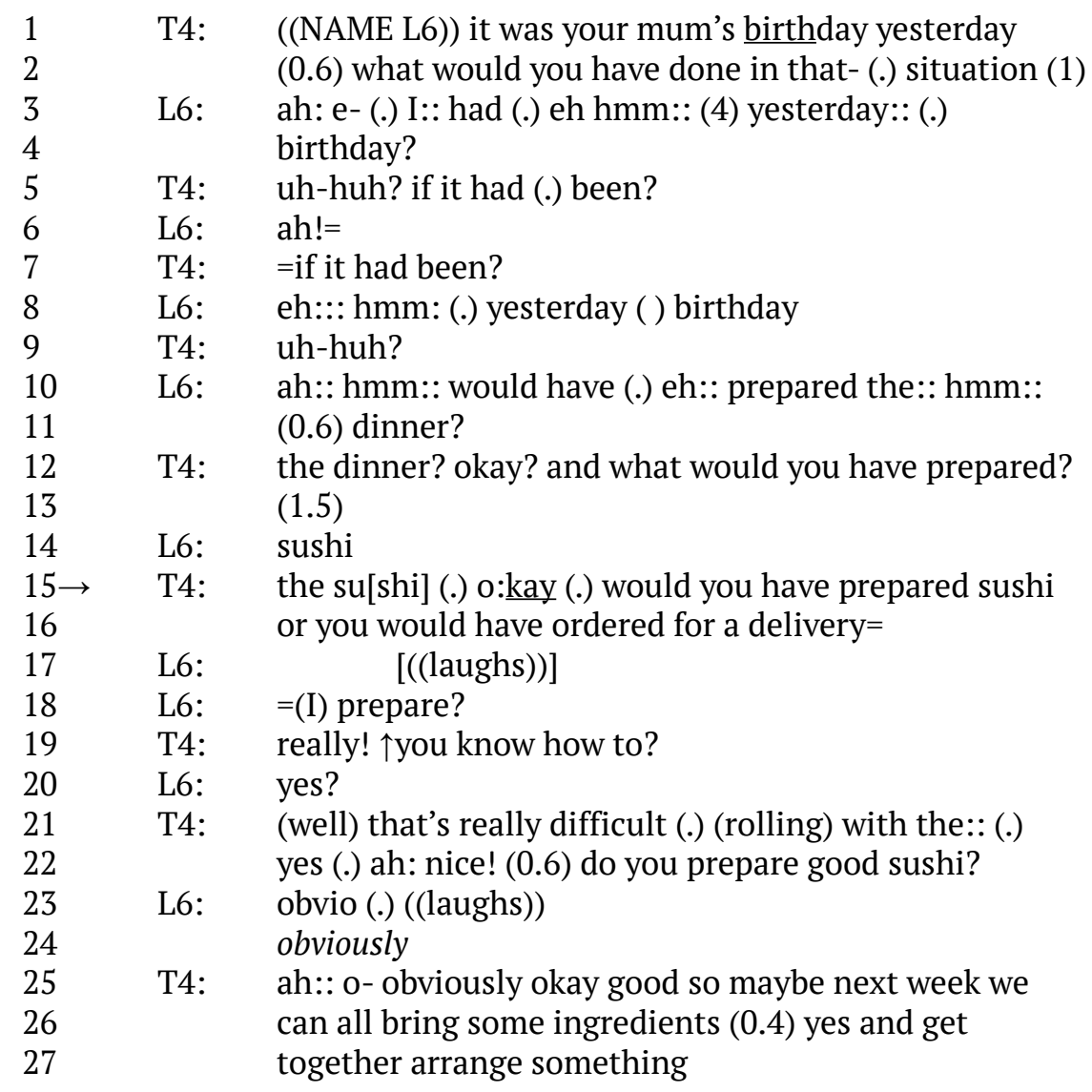

In Extract 2, the class is checking a textbook activity on the use of conditionals. After nominating L6 to read a sentence from the textbook in line 10, T4 performs a CCM 'side sequence' (Walsh, 2006) and asks a series of questions that seek to elicit meaningful talk from L6. She first asks what L6 would have prepared for dinner (line 12), which is a rather closed question in the sense that the answer does not typically require a long turn. L6 orients to the closed nature of the question by providing a one-word answer ('sushi') in line 13. T4 repeats the lexical item and goes on to ask the next question. This time, T4 asks a closed question in the form of an either/or question (lines 15-16). L6 replies to the question with a very short TCU that includes the verb that T4 used in the question (line 18). Then, T4 provides content feedback on L6's ability to prepare sushi. At this point in the interaction, it could be argued that T6 is still orienting to the Materials mode, as she includes in her questions the conditional forms that learners have seen in the textbook. However, as can be seen in lines 15 and 19, her feedback to L6's answers is content-related and does not seek to elicit such forms from L6. This suggests that T4 does indeed initiate the mode side sequence in line 15. T4 then asks another yes/no question in line 19, which is followed by L6's affirmative token. Again, T4 reacts to L6's short answers by producing content feedback on the difficulty in preparing sushi. This is followed by T4's yes/no question about L6's ability to prepare good sushi (line 22). This time, L6 has decided to provide a different answer to a yes/no question and,

\footnotetext{
2 In the Materials mode, the main pedagogical goal is to work with reference to the materials being used. IRF sequences and display questions are typical in this mode, as teachers aim to elicit accurate responses from learners and provide feedback on form. Due to this, there is very little interactional space for learners (Walsh, 2013).
} 
unable or unwilling to do the word search for the word obviously in English, she codeswitches to her L1 (Spanish 'obvio', in line 23). T4 translates the word into English and, once again, provides immediate content feedback. The CCM side sequence in Extract 2 (lines 15-27) can then be characterised by long teacher turns and by the absence of long learner turns. Content feedback provided by T4 in lines 15, 19, 21, and 25 did not elicit further talk from the learner. The wait time provided by T4 (line 13) did not encourage learner participation either. The ineffectiveness of these features in promoting learner output can be explained in terms of the closed nature of the questions asked by T4. A closed question restricts the output produced by learners, but it can also prevent any further contributions that learners may want to make, as they may feel that their 'second pair part' (Schegloff \& Sacks, 1973) in the question-answer adjacency pair has been completed, however short it may be. This suggests that providing content feedback to one-word answers and wait-time after a closed question may not be enough to facilitate opportunities for participation and learning when the pedagogical goal is to initiate and sustain communication. In contrast, Extract 3 presents a different approach to eliciting learners' answers after the first closed question is asked. This interaction belongs to a lesson with intermediate-level learners and portrays a mode side sequence where the teacher momentarily switches from a reading comprehension correction activity (Materials mode) to a discussion generated from the sentences being corrected (CCM). Here, T3 asks closed questions but demonstrates a better understanding of CIC and the functions that these questions can have in the discourse in a context where fluency and communication are the main pedagogical goals.

Extract 3: T3. Boss.

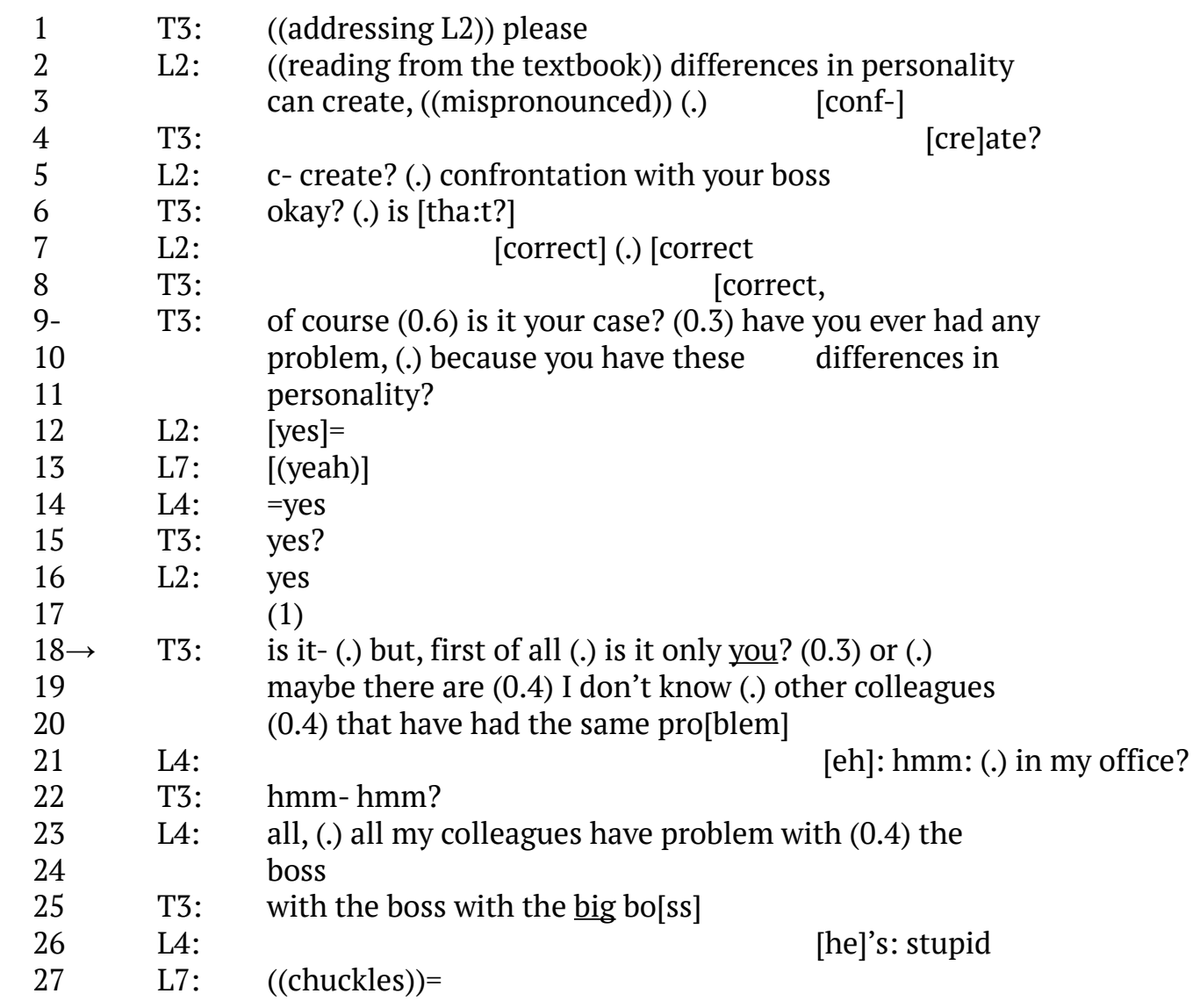

The side sequence into a CCM starts in lines 9-11, where T3 asks two closed questions that require a yes/no answer about learners' problems with their bosses. The two questions in the turn are separated by a short pause, and the second question is a reformulation of the first one, as it seeks to make the meaning of the first one more specific. These closed questions are asked first in order to make learners feel more included in the interaction, and are 'invitations to reply' (Mehan, 1979) because students are expected to reply without being nominated by the teacher. Although teacher gestures were not captured, it seems as if T3 did not select the next speaker, as three learners self-selected and answered the question (lines 12-14). These affirmative tokens did not prompt further elaboration by the learners, so after a one-second pause she decides to ask another 
closed question in lines 18-20. T3 does not provide immediate content feedback to the single-word tokens provided by learners (lines 12-14); instead, she produces a turn (lines 18-20) that requires closer analysis. T3 does acknowledge learners' affirmative tokens (line 15) but instead of providing content feedback, she produces 'first of all', an expression that projects further talk and is followed by the question 'is it only you?' as she is interested in knowing whether the problems with her learners' bosses have affected their colleagues. Once this question is asked, she makes a very short pause (0.3) and turns the question into an either/or question, by adding a second option. This is done to clarify the question to the learners, as there is not enough information in the yes/no question to elicit an answer from them, even in short form. In this attempt to clarify the question, T3 'disguises' it as a more open question by including an adverbial of uncertainty ('maybe') and an epistemic marker ('I don't know') in its elaboration (line 19), which displays T3's epistemic stance (Heritage, 2012) regarding possible answers to the questions and invites learners to provide a more informative answer. Thus, a question that was meant to be a closed yes/no question has been modified by T3 in such a way that its answer will require something more than a yes/no token or the mere repetition of a sequence of words included in the question. The closed question asked in lines 18-20 prompted L4 to self-select and provide an account of her situation with her boss whilst producing three turns (lines 21, 23-24, and 26). Following this, it can be argued that when a closed question is asked as part of a CCM, the replacement of content feedback by additional questions when single-word tokens are produced, and the manner in which a closed question is disguised, can elicit more complex and meaningful answers from learners. The addition of these epistemic markers after a closed question is asked can force learners to orient to the content of what is being said by the teacher as part of the question rather than to the closed nature of the question being asked, which can encourage higher-level processing and participation from learners, as was seen in Extract 3.

\section{Open Referential Questions as Initiators of CCM}

As previously stated, referential questions are questions to which the teacher does not have an answer, and they generate interactions more typical of social communication; display questions create discourse that is more didactic and seek to confirm knowledge (Tsui, 1995). Although referential questions elicit more talk, when they are more closed the opportunities for learners to produce longer stretches of talk may be reduced, as was seen in Extract 2 (lines 12-24) and Extract 3 (lines 9-17). Referential questions will be discussed here primarily by taking into consideration the role they can have as 'initiators' of a CCM sequence. In particular, the focus was placed on the shift from a Materials mode to a CCM by means of a mode side-sequence (Walsh, 2006). Learner participation was increased when open referential questions that initiate CCM side sequences are asked, as they can open up and shape new interactional sites for learners to explore. Extract 4 and 5 are sequences found in two different groups managed by the same teacher (T2). They both contain referential questions, and they are both instances where learner participation is generated by those questions. The focus of the analysis is placed on the context in which the question 'why are you laughing?' is being asked in both extracts. Extract 4 is presented below.

Extract 4: T2. Contests.

$\begin{array}{lll}1 & \text { T2: } & \text { eh: when you were living in Spain (1) did you watch tv? (.) } \\ 2 & \text { L1: } & \text { yes= } \\ 3 & \text { L6: } & \text { =yes } \\ 4 & \text { L1: } & {[((\text { laughs }))]} \\ 5 & \text { L6: } & \text { [((laughs))] } \\ 6 \rightarrow & \text { T2: } & \text { why are you laughing? is it too different to Chilean TV? } \\ 7 & \text { L6: } & \text { yes (.) all day eh:: (0.4) eh:: in the afternoon (.) there } \\ 8 & & \text { are many: (.) eh: TV programme? (.) eh:: (.) concursos (.) }\end{array}$

T2: $\quad$ contests $(0.6)$ contests

L6: contests (.) eh:: programme (0.4) during- eh:: (0.9) con

-g- many peoples hhh (.) eh::=

L2: $\quad$ ((chuckles))

T2: $\quad$ many people?

L6: $\quad$ many people (.) eh:: (.) participant (.)

T2: uh-huh?= 


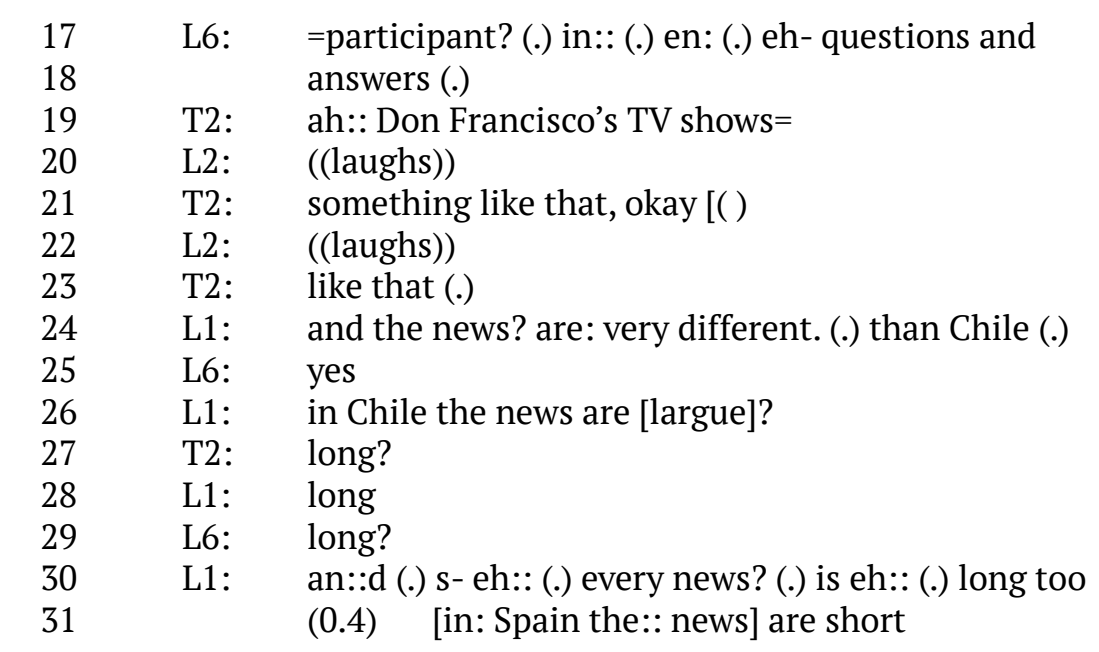

T2 is asking L1 and L6 about their trip to Spain. This is being done within a CCM, where T2 is attempting to elicit learners' opinions on cultural differences between countries. T2's closed referential question 'When you were living in Spain did you watch TV?' is answered by L1 and L6 with affirmative tokens, which precede their laughter in lines 4 and 5. These short laughter tokens are TCUs that triggers T2's open referential question 'why are you laughing?', followed by the more closed question 'is it too different to Chilean TV?' (line 6). T2 demonstrates CIC here as she is being sensitive to the learners' potential reactions that can trigger subtopic development. This interactional strategy is in line with the pedagogical goals that $\mathrm{T} 2$ has as part of a classroom context mode, i.e. eliciting learner talk and promoting fluency. Although the open referential question in line 6 is followed by a more closed referential question, L6 still orients to both questions when producing an answer in lines 7-8. Interestingly, a closed question such as 'Is it too different to Chilean TV?' projects an answer that is elaborated on with more than an affirmative or negative token. Some of the errors made by L6 and L1 are swiftly repaired by $\mathrm{T} 2$. The rising contour T2 gives to the items being repaired (lines 14 and 27) also allows L6 (line 15) and L1 (line 30) to hold the floor and finish their ideas. T2's provision of backchannel feedback (line 16) and content feedback throughout the sequence (particularly when it conveyed a change in epistemic status, such as 'ah' in line 19) also suggests that T2 was orienting to eliciting answers and discussing meanings. Thus, it can be stated that the open referential question produced by T2 in line 6 was skilfully asked in order to fulfil the pedagogical goal set by $\mathrm{T} 2$ at that moment. In other words, this question served the purpose of eliciting more answers from elementary level learners in relation to a topic that was already being discussed within a CCM. Extract 5 below portrays an interaction where a mode side sequence from the Materials mode (textbook activity) to the CCM begins in line 7.

Extract 5: T2. Computer.

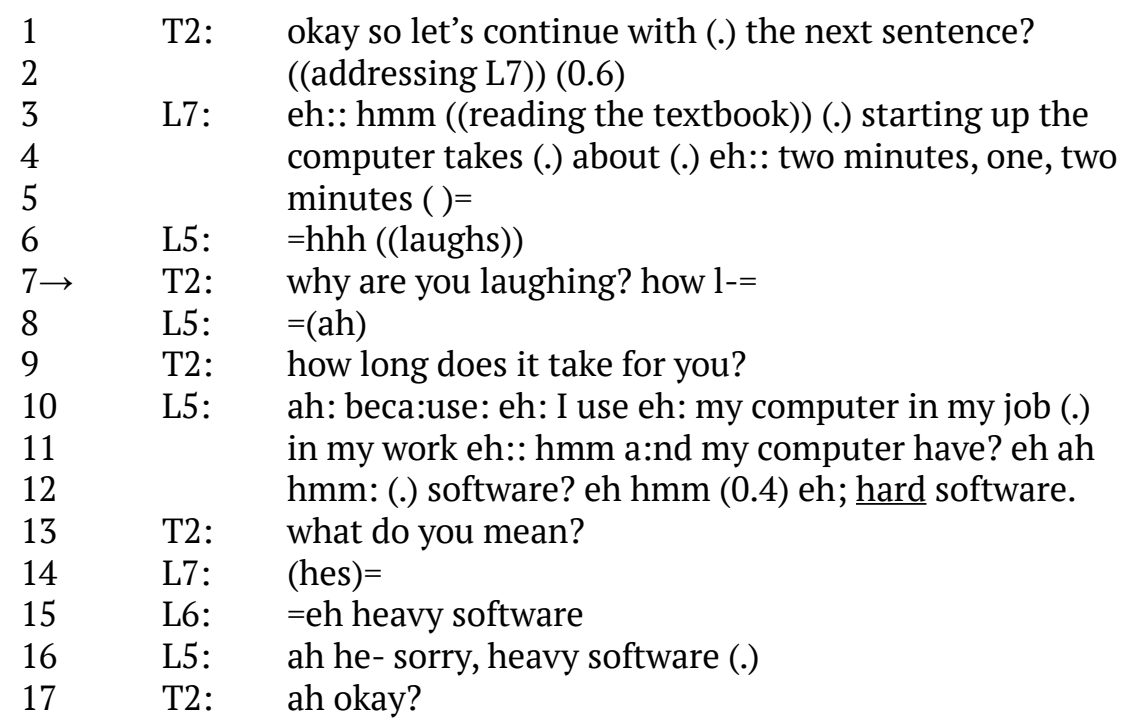




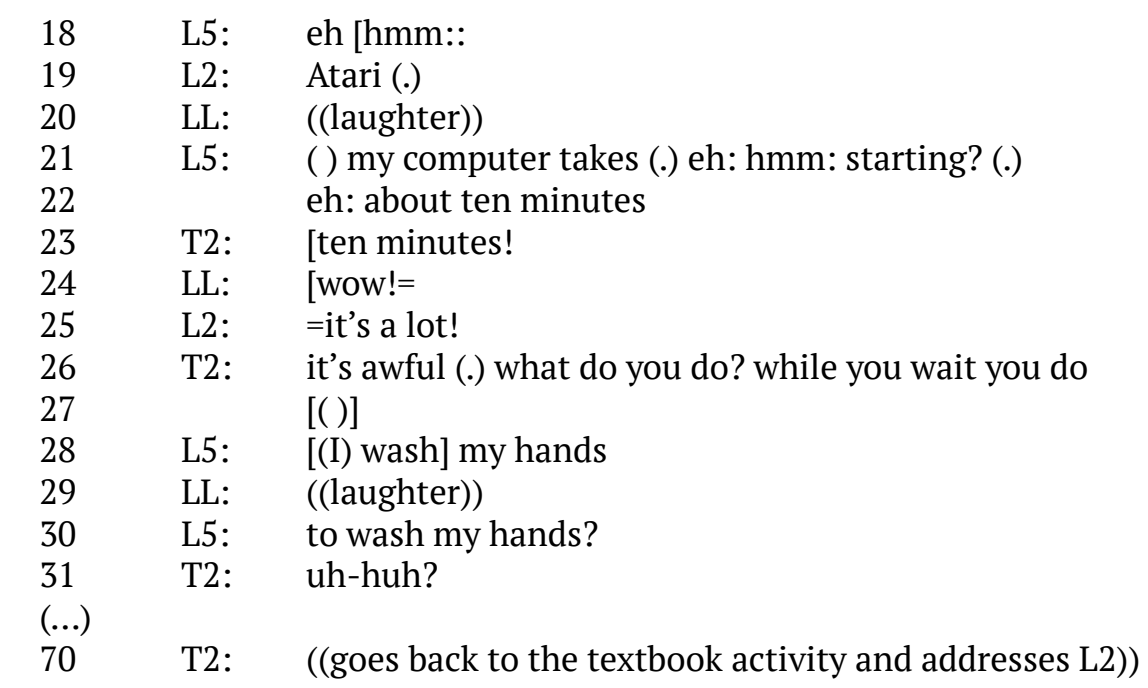

In this sequence, $\mathrm{T} 2$ is checking the answers to a textbook activity that reviews the use of 'it takes' when used with time expressions. T2 has nominated L7 to read a sentence from the exercise. As L7 finishes the sentence, her utterance is latched to L5's aspiration and laughter in line 6. T2 orients to this laughter in line 7 and asks L5 'why are you laughing?' As was the case in Extract 4, a learner's laughter has triggered T2's open referential question, which is phrased in the same way in both extracts. However, unlike the open referential question asked in Extract 4 (line 6), this open referential question is initiating a mode side sequence where T2 momentarily moves from a Materials mode to a CCM. The open referential question asked by T2 is followed by her attempt to ask the more contextualised question 'how long does it take for you?'. The way in which T2 follows her delivery of 'why are you laughing?' in reaction to the learner's laughter TCUs in both extracts is quite similar; in Extracts 4 (line 6) and 5 (line 7), T2 asks a more closed referential question after the first one. Also, T2's second question is more closed in nature and provided the recipients with more context in which to build their turn. L5 interrupts T2's first attempt to ask the question and latches a hesitation marker ('ah') to T2's unfinished contribution (line 8). T2 asks the completed second referential question in the next turn. This is followed by L5's explanation of the reasons why she laughed, which are related to the fact that her own computer takes a lot of time to start up. The ensuing mode side sequence is characterised by T2's content feedback (lines 23 and 26), backchannel feedback (lines 17 and 31), clarification requests (line 13), and a departure from the IRF turn-taking pattern. Although it could be argued that L5 is still orienting to the structure being learned (the use of take with time expressions) in line 21, the manner in which this turn is managed by T2 suggests that the mode side sequence is in full effect; T2 does not correct L5's error and provides non-evaluative feedback (line 23 and 26), which are distinctive features of a CCM. Thus, it can be stated that the mode side sequence taking place in Extract 5 has made T2 move away from eliciting responses in relation to the materials being used and language practice with a particular structure (lines 1-5) toward co-constructing a sequence where learners have more space to express themselves and where their meaningful contributions are being encouraged (Walsh, 2006). Interestingly, the open referential question 'why are you laughing?' has been triggered by a learner's laughter and has promoted learner participation in both extracts. The context in which the open referential question was delivered is, however, quite different. In Extract 4, T2 asked the question as part of a CCM that was in full operation, whilst in Extract 5, T2 asked the same question when the Materials mode was in place. Unlike open referential questions that are part of CCMs, open referential questions that initiate a CCM require teachers to scan learners' responses, gestures, and body movements when engaging in other modes, as these can potentially trigger an open referential question and initiate a CCM switch or mode side sequence, which is the case in Extract 5. In this extract, T2 has been sensitive to learners' reactions to the ongoing practice with the materials and has oriented to them in order to generate a CCM. These findings are in line with Waring et al. (2016), who found that certain unexpected learner contributions can be tactfully managed by the teacher to achieve a particular pedagogical trajectory.

Opportunities for asking open referential question initiators of a CCM are being missed when the teacher fails to notice potential triggers. Extract 6 below is an episode that is part of a Materials mode where T4 is checking responses for an activity that involves the use of cards. These cards contain a question that prompts learners to use a conditional structure. 
Extract 6: T4. Supermarket.

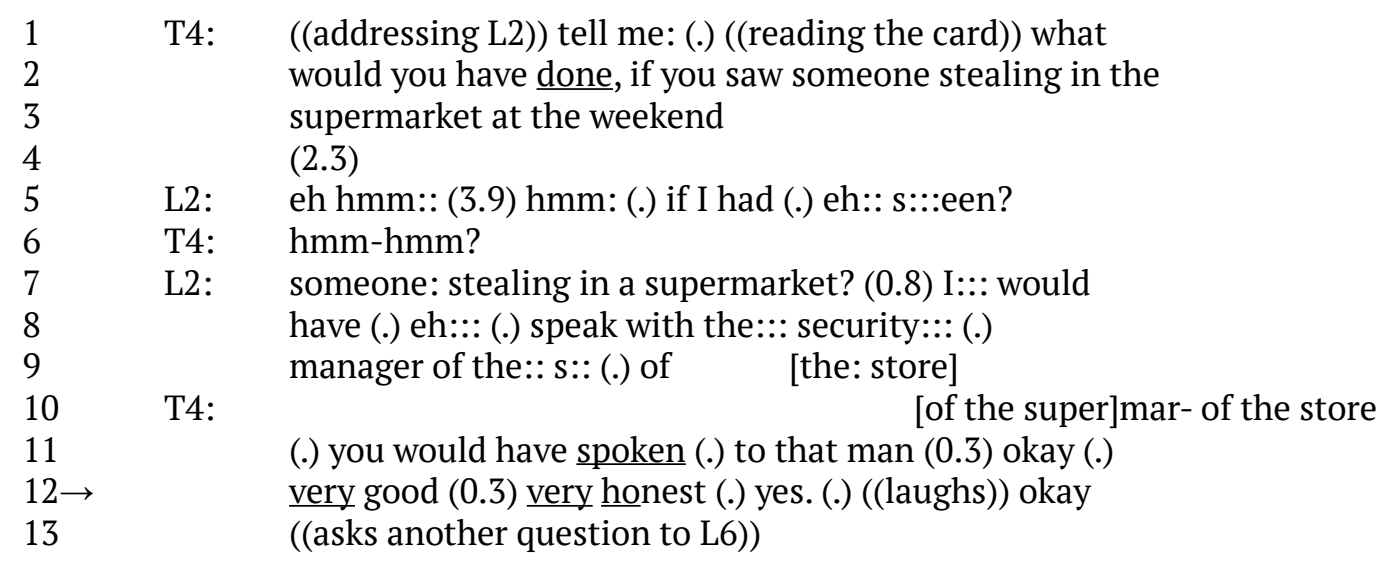

Extract 6 portrays an interaction that belong to a Materials mode, as discourse is being dictated by the materials being used, and an IRF pattern and form-focused feedback are given by T4. Nonetheless, the focus of the analysis is placed on line 12 . Here, T2 produces TCUs that are arguably not evaluative. The first one is 'very good', which would typically be seen in a Materials mode as positive evaluative feedback in the third turn of an IRF sequence (Wong \& Waring, 2009). In this context, however, it seems that T4 is orienting to the meaning of L2's utterance (the idea that L2 would have spoken to the security manager) rather than to its form. It is unlikely that T4 would produce 'very good' as a linguistic evaluation of L2's turn since it contained an error ('speak' in line 8) which was corrected by T4 (line 11). The next TCU in line 12 is 'very honest', which orients to the content of L2's contribution and is followed by an affirmative token and T4's laughter. When T4 nominates L6 to repeat the same sequence (line 13), T4 has lost the opportunity to exploit L2's TCUs as a trigger to initiate a CCM side sequence. Even though she attempts to orient to the meaning of L2's utterance by providing content feedback, she is unable (or unwilling) to use this as a platform from which to ask a referential question that orients to topic development, which would have engaged L2 and probably other learners in meaningful conversation.

The unpacking of the interactions in the selected extracts has yielded a number of findings. It was found that providing content feedback in the third turn of the IRF - that is, after a closed question such as a yes/no question has been answered - may prompt learners to regard their role in the interaction as fulfilled (Extracts 1 and 2). Thus, content feedback provided in the third turn after a closed question is asked as part of an IRF sequence in a CCM was not found to elicit more talk from learners. There are steps that can be taken to address this lack of learner talk. Teachers could benefit from understanding that asking a closed question is only the first step in the process of eliciting answers from learners. This is a first step that has a purpose because it can initiate a topic and, if it is done by nominating the whole class, it can make learners feel they are all being part of the interaction. After a closed question is asked, teachers can immediately ask more open referential questions or 'disguise' a closed question as a more open question. This can be done by using epistemic markers that help display an inferior epistemic stance (Heritage, 2012), which can prompt learners to elaborate on their answers and engage in higher cognitive processing before answering (Extract 3). It must be noted that certain features of interactions that are typically accepted and encouraged in contexts that seek to develop fluency may not always be used appropriately. In line with Cancino (2015), it was found that a teacher strategy such as the provision of content feedback facilitated or hindered learner involvement in this context depending on whether "the teacher interpret[ed] the local intricacies of the unfolding interaction in context-sensitive ways" (p. 13). This can be seen in Extract 3, where content feedback is immediately provided after a learner replies to a closed question with a single-word token, which reduced learner involvement.

Referential questions were analysed in terms of the benefits that can be gained from a strategy that allows teachers to evaluate learners' contributions not only in terms of their correctness but also in terms of their potential value as triggers of a CCM. It is argued that referential questions can initiate a classroom mode sequence or mode switch and the resulting sequence can be as beneficial to learners as a referential question that is already part of a CCM (Extracts 4 and 5). In order for teachers to initiate a CCM sequence, they must be very sensitive to potential triggers in learners' turns that can allow them to ask a referential question and skilfully steer the interaction towards a CCM. As the analysis of Extract 6 suggests, if teachers repeatedly fail to 
notice and react to these triggers then opportunities for more meaningful interaction and participation will be missed.

\section{Conclusion}

Analysis of the extracts has suggested that teachers can demonstrate classroom interactional competence by attending to contextual features in the interaction as they elicit language from their learners. Two aspects in the elicitation of questions were identified, namely, the effective management of closed questions, and the use of open referential questions as initiators of a CCM. These novel elicitation resources can promote a facilitatororiented approach to teaching because they can elicit more learner talk and grant greater participation rights in a CCM. Consequently, the value of the identified elicitation resources lies in their potential to initiate and sustain a CCM, as well as their inclusion in a framework that seeks to develop teachers' classroom interactional competence. When open referential questions are asked in a context that can potentially initiate a CCM, they may not be fully exploited by teachers because they are not asked while taking into account the moment-bymoment nature of the interaction. This may result in opportunities for learning and participation that are not capitalised upon. Indeed, asking a referential question is only the first step; teachers should be aware of learners' replies and optimise them by building on them. Open referential questions that initiate and sustain CCM interactions can exploit these aspects and are to be encouraged. As these questions are initiated as parts of other modes, the amount of learner participation and involvement in the production of meaningful interaction is increased, which is desirable in EFL classrooms, where the opportunities for teachers to develop fluency and promote communication need to be maximised. If specific pedagogical goals can influence the effectiveness of display and referential questions in particular pedagogical contexts, teachers need to be aware of elicitation resources that can help them meet those pedagogical goals in the CCM. Teachers typically forget to switch back to a CCM when they initiate mode side sequences that include explanations of grammar points or explaining a lexical item. What is argued here is that doing quite the opposite - that is, asking open referential questions that initiate a CCM side sequence - should be encouraged in an EFL context, as these interactional resources can provide learners with target language practice elicited through their own ideas and feelings. Exploiting these types of questions requires teachers to listen to what learners are saying in other modes (such as the Materials mode) and regard their contributions not only just as utterances that need to be evaluated in terms of their accuracy, but also in terms of how they can potentially initiate CCMs. The CCM is a very important stage in the language classroom, but it becomes crucial in EFL contexts. In these contexts, opportunities are scarce for learners to use the target language once they leave the classroom, so when teachers fail to promote and sustain the meaningful interactions that takes place in the CCM, learners are left without a critical aspect of language learning. Thus, identifying ways to initiate and sustain the CCM by means of eliciting questions should be encouraged and nurtured in a teacher's set of interactional strategies.

\section{References}

Atkinson, J., \& Heritage, J. (1984). Transcript notation. In J. Atkinson \& J. Heritage (Eds.), Structures of Social Action: Studies in Conversation Analysis (pp. IX-XVI). Cambridge: Cambridge University Press.

Barahona, M. (2016). Challenges and accomplishments of ELT at primary level in Chile: Towards the aspiration of becoming a bilingual country. Education Policy Analysis Archives, 24, 82. doi:10.14507/epaa.24.2448

Brock, A. (1986). The effects of referential questions on ESL classroom discourse. TESOL Quarterly, 20(1), 47-59.

Cancino, M. (2015). Assessing learning opportunities in EFL classroom interaction: What can conversation analysis tell us?. RELC Journal, 46(2), 115-129. doi:10.1177\%2F0033688214568109

Cancino, M. (2017). Shaping learner contributions in the EFL language classroom: A conversation analytic perspective. Lenguas Modernas, (49), 53-75.

Cullen, R. (1998). Teacher talk and the classroom context. ELT Journal, 52(3), 179 - 187.

Ellis, R., \& Barkhuizen, G. (2005). Analysing learner language. Oxford: Oxford University Press.

Glas, K. (2008). El inglés abre puertas. . ¿A qué? Análisis del discurso sobre la enseñanza del inglés en Chile, 2003-2006. Revista Educación y Pedagogía, 20(51),11-122.

Gómez, E. \& Pérez, S. (2015). Chilean 12th graders' attitudes towards English as a foreign language. Colombian 
Applied Linguistics, 17(2), 313-324. doi: 10.14483/udistrital.jour.calj.2015.2.a10

Heritage, J. (1997). Conversational analysis and institutional talk: analyzing data. In D. Silverman (Ed.), Qualitative research: Theory, Method and Practice (pp. 161-182). London: Sage Publications.

Heritage, J. (2012). Epistemics in action: Action formation and territories of knowledge. Research on Language and Social Interaction, 45(1), 1-29. doi: 10.1080/08351813.2012.646684

Hutchby, I., \& Wooffitt, R. (2008). Conversation analysis. Cambridge: Polity.

Jafari, J. (2013). The role of elicitation questions in language learning: A function-based framework. Anchor Academic Publishing.

Kasper, G., \& Wagner, J. (2011). A conversation-analytic approach to second language acquisition. In D. Atkinson (Ed.), Alternative approaches to second language acquisition (pp. 117-142). New York: Taylor \& Francis.

Lazaraton, A. (2004). Conversation analysis and the nonnative English speaking ESL teacher: A case study. In D. Boxer \& A. Cohen (Eds.), Studying speaking to inform second language learning (pp. 49-57). Clevedon: Multilingual Matters.

Lee, Y.A.(2006). Respecifying display questions: Interactional resources for language teaching. TESOL Quarterly, 40(4), 691. doi:10.2307/40264304

Lee, W., \& Ng, S. (2010). Reducing student reticence through teacher interaction strategy. ELT Journal, 64(3), 302-313. doi: 10.1093/elt/ccp080

Markee, N. (2004). Zones of interactional transition in ESL classes. The Modern Language Journal, 88(4), 583-596.

Markee, N. (2015). The handbook of classroom discourse and interaction. John Wiley \& Sons.

Matear, A. (2008). English language learning and education policy in Chile: Can English really open doors for all? Asia Pacific Journal of Education, 28 (2), 131-147. doi: 10.1080/02188790802036679

Mehan, H. (1979). Learning lessons: Social organization in the classroom. Cambridge: Harvard University Press.

Ministerio de Educación. (2009). Fundamentos del Ajuste Curricular en el sector de Idioma Extranjero, Inglés. Santiago: Gobierno de Chile.

Nunan, D. (1989). Understanding language classrooms: A guide for teacher initiated action. New York: PrenticeHall.

Ortega, L. (2011). SLA after the social turn. In D. Atkinson (Ed.), Alternative approaches to second language acquisition (pp. 167-180). New York: Taylor \& Francis.

Pekarek Doehler, S. (2010). Conceptual changes and methodological challengse: On language and learning from a conversation analytic perspective on SLA. In Conceptualising 'learning' in applied linguistics (pp. 105-126). New York: Palgrave Macmillan.

Pomerantz, A., \& Fehr, B. (1997). Conversation analysis: An approach to the study of social action as sense making practices. In T. van Dijk (Ed.), Discourse as social interaction (pp. 64-91). London: Sage Publications.

Sacks, H., Schegloff, E., \& Jefferson, G. (1974). A simplest systematics for the organization of turn-taking for conversation. Language, 50(4): 696-735.

Schegloff, E. \& Sacks, H. (1973). Opening up closings Semiotica, 8: 289-327.

Seedhouse, P. (2004). The interactional architecture of the language classroom: a conversation analysis perspective. U.K: Blackwell Publishing.

Seedhouse, P., \& Walsh, S. (2010). Learning a second language through classroom interaction. In P. Seedhouse, S. Walsh \& C. Jenks (Eds.), Conceptualising 'learning'in applied linguistics (pp. 127-146). Palgrave Macmillan, London.

Sert, O. (2015). Social interaction and L2 classroom discourse. Edinburgh: Edinburgh University Press.

Sinclair, J., \& Coulthard, M. (1975). Towards an analysis of discourse. London: Routledge.

Thornbury, S. (1996). Teachers research teacher talk. ELT Journal, 50(4), 279-289. doi: 10.1093/elt/50.4.279

Tsui, A. (1995). Introducing classroom interaction. London: Penguin.

Walsh, S. (2002). Construction or obstruction: teacher talk and learner involvement in the EFL classroom. Language Teaching Research. 6(1): 3-23. doi: 10.1191\%2F1362168802Ir095oa

Walsh, S. (2006). Investigating classroom discourse. London: Routledge.

Walsh, S. (2011). Exploring classroom discourse: language in action. Abingdon: Routledge.

Walsh, S. (2013). Classroom discourse and teacher development. Edinburgh: Edinburgh University Press.

Waring, H. (2008). Using explicit positive assessment in the language classroom: IRF, feedback, and learning opportunities. The Modern Language Journal, 92(4), 577-594. doi: 10.1111/j.1540-4781.2008.00788.x

Waring, H. (2009). Moving out of IRF (initiation-response-feedback): A single case analysis. Language Learning, 59(4), 796-824. doi: 10.1111/j.1467-9922.2009.00526.x

Waring, H. (2011). Learner initiatives and learning opportunities in the language classroom. Classroom Discourse, 2(2), 201-218. doi: 10.1080/19463014.2011.614053 


\section{LEARNER PARTICIPATION THROUGH ELICITING LANGUAGE}

Waring, H. (2012). "Any questions?": Investigating the nature of understanding-checks in the language classroom. Tesol Quarterly, 46(4), 722-752. doi: 10.1002/tesq.48

Waring, H. (2019). The what and how of English language teaching: Conversation analytic perspectives. In X. Gao (Ed.), Second handbook of English language teaching (pp. 1053-1070). New York: Springer.

Waring H., Reddington, E., \& Tadic, N. (2016). Responding artfully to student-initiated departures in the adult ESL classroom. Linguistics and education, 33, 28-39. doi: 10.1016/j.linged.2015.12.001

Wong, J., \& Waring, H. (2009). 'Very good' as a teacher response. ELT Journal, 63(3), 195-203. doi: 10.1093/elt/ ccn042 


\section{MARCO CANCINO}

\section{Appendix}

\section{Transcription conventions (adapted from Atkinson \& Heritage, 1984)}

T: $\quad$ Teacher

L1: $\quad$ Identified learner (e.g., Learner 1)

NAME: A specific learner is being nominated in the interaction (e.g., NAME L1)

[ ] Overlapping utterances. Overlap onset: ( [ ). Overlap termination: ( ] )

$=\quad$ An equal sign is inserted at the end of one speaker's turn and at the beginning of the next speaker's turn to show that there is no gap between the turns.

(0.4) Periods of silence, timed in tenths of a second between utterances.

Micropauses, that is, pauses lasting less than 0.3 seconds, are symbolised '(.)'; longer pauses appear as time within parentheses: (0.5) is five tenths of a second.

: $\quad$ Sound extension of a word (more colons demonstrate longer stretches).

Fall in tone (not necessarily the end of a sentence).

Continuing intonation (not necessarily between clauses).

An abrupt stop in articulation.

Rising inflection (not necessarily a question).

Words ending with emphasis.

They surround talk that is quieter.

$\uparrow \downarrow \quad$ Indication of sharply higher or lower pitch in the utterance followed by the arrow.

hhh Audible in-breath. The more h's, the longer the in-breath.

.hhh Audible out-breath. The more h's, the longer the out-breath.

$>\quad$ They surround talk that is spoken faster than neighbouring talk.

$\quad$ They surround talk that is spoken slower than neighbouring talk.

(()) Analyst's notes. Non-vocal action. Details of scene.

( ) Approximations of what is heard. Words within parentheses are uncertain.

word Underlined letters or words indicate marked stress.

italics. English translation, immediately after the original word(s).

$\rightarrow \quad$ Feature of special interest. 